UDC 1:159.922.262

LBC 87.524.1

\title{
ARCHITECTURAL SPACE OF THE CITY AS A FACTOR OF IDENTITY FORMATION (EXEMPLIFIED BY THE CITY OF VOLGOGRAD)
}

\author{
Viktoriya A. Khrapova \\ Volgograd State University, Volgograd, Russian Federation \\ Maria A. Latysheva \\ Volgograd State Technical University, Volgograd, Russian Federation
}

\begin{abstract}
The article is devoted to the study of the architectural space of the hero-city of Volgograd and its role in the formation of urban identity. The methodological basis is the cultural-historical approach, phenomenological and hermeneutic methods. It is concluded that the disparate eclectic architectural environment does not contribute to the creation of regional identity, does not develop ideas about the uniqueness of the place, which negatively affects the formation of the city image and urban identity. At the same time, a conscious approach to the organization of the architectural environment in any of its forms can become the soft power of implicit management, a prerequisite for resource states, a technology for harmonizing and optimizing social space. The scientific novelty of the research consists in the explication of the mechanism of architectural space influence on a person as a biopsychosocial being. The authors distinguish archetypal, symbolic, and conceptual levels of perception, showing that the influence of the archetypal is implicit but necessary. This is the level of perception at the level of sensations, which are the basis of feelings, are the prerequisite for emotions and mental attitudes. This lies at the origins of the identity formation as the involvement of a person in the significant experience of the past, others, relatives. Symbolic and conceptual levels of perception are related to the process of cognition, rational and logical attitudes. In the conditions of modern social dynamics, a competent organization of the architectural landscape, which contributes to the optimization and harmonization of living activities, can become an important factor of integration and a prerequisite for the formation of a positive identity. The authors consider that modern identity can be formed in the course of new practices that remove traditional restrictions around life-affirming values and meanings that underlie the organization of the living environment, taking into account the principles of ecology.
\end{abstract}

Key words: architecture, identity, perception, harmonization, space, soft management, Volgograd.

УДК 1:159.922.262

ББК 87.524 .1

\section{АРХИТЕКТУРНОЕ ПРОСТРАНСТВО ГОРОДА КАК ФАКТОР ФОРМИРОВАНИЯ ИДЕНТИЧНОСТИ (НА ПРИМЕРЕ ГОРОДА ВОЛГОГРАДА)}

\author{
Виктория Анатольевна Храпова \\ Волгоградский государственный университет, г. Волгоград, Российская Федерация
}

Мария Александровна Латышева

Волгоградский государственный технический университет, г. Волгоград, Российская Федерация

Аннотация. Данная статья посвящена изучению роли архитектурного пространства города-героя Волгограда в формировании городской идентичности. Методологическую основу исследования составляет 
культурно-исторический подход, дополненный применением феноменологических и герменевтических методик. Сделан вывод о том, что разрозненная эклектичная архитектурная среда не способствует созданию региональной самобытности, не развивает представления об уникальности места, что негативно сказывается на формировании имиджа города и городской идентичности. Вместе с тем, осознанный подход к организации архитектурной среды в любых ее формах может стать «мягкой силой» неявного управления, предпосылкой ресурсных состояний, технологией гармонизации и оптимизации социального пространства. Научная новизна исследования состоит в экспликации механизма влияния архитектурного пространства на человека как биопсихосоциального существа. Авторы выделяют архетипический, символический и концептуальный уровни восприятия, показав, что влияние архетипического является неявным, но обязательным. Это уровень восприятия на уровне ощущений, которые лежат в основе чувств, являются предпосылкой эмоций и ментальных установок. Именно он находится у истоков формирования идентичности как причастности человека к значимому опыту прошлого, других, близких. Символический и концептуальный уровни восприятия связаны с процессом познания, рационально-логическими установками. В условиях современной социальной динамики грамотная организация архитектурного ландшафта, способствующая оптимизации и гармонизации жизнедеятельности людей, может стать важным фактором интеграции и предпосылкой формирования позитивной идентичности. Как представляется авторам статьи, современная идентичность может формироваться в ходе новых практик, снимающих традиционные ограничения вокруг жизнеутверждающих ценностей и смыслов, которые лежат в основе организации жизненной среды с учетом принципов экологии.

Ключевые слова: архитектура, идентичность, восприятие, гармонизация, пространство, мягкое управление, Волгоград.

В современном мире идет процесс социальной трансформации, сопряженный с интенсивным развитием информационных технологий. Меняется традиционный контекст формирования идентичности. В одной из своих работ «Город-генерик» архитектор и теоретик Рем Колхас отметил: «Поскольку происхождение идентичности принято связывать с физической субстанцией, с историей, с контекстом, с чемто реальным, мы как-то не в состоянии допустить, что в ее формировании может участвовать и нечто современное - сделанное нами. $<\ldots>$ Идентичность, понимаемая как коллективно разделяемое прошлое, - это заранее проигранная ставка. И дело не только в том, что доля, причитающаяся каждому, при стабильно растущем населении становится все меньше и меньше, - история, кроме того, обладает неприглядным свойством распадаться, подобно радиоактивным материалам: чем сильнее ее эксплуатируют, тем менее значимой она становится...» [Колхас 2015, 18]. Вместе с тем, человек всегда нуждается в смыслах, привносящих ценность в его жизнь, в поддержке и признании, базирующихся на общем понимании ценностей, причастности к великому или обыденному опыту, дарующему ясность и перспективы. Важную роль в формировании идентичности играет архитектурное пространство.

Архитектура является плодом мощных масштабных интеллектуальных и творческих усилий. Она соединяет прошлое и настоящее, определяет конфигурацию среды, в которой осуществляется жизнь нескольких поколений, закладываются основы формирования личности, осуществляются профессиональные и межличностные контакты, устанавливаются социальные связи. Это пространство, в котором делаются выборы и принимаются судьбоносные решения. Архитектура является также важной составляющей визуального образа города, играет роль в оформлении его имиджа.

Рассмотрим, как развивается процесс формирования городской идентичности в архитектурном пространстве Волгограда.

Исторически город формировался вдоль побережья Волги. Как отмечает исследователь архитектуры и искусствовед Ю.В. Янушкина, «пространственно-смысловая структуpa, сообразно которой осваивалась территория города Царицына - Сталинграда - Волгограда, представлена регулярной сетью улиц с центральным ядром в виде раскрывающейся к Волге площади. Сформировавшись под влиянием ландшафтных условий в XVII в., исходная структура проявляется с различной степенью подобия как на уровне проектных концепций города, так и на уровне их осуществления в различные периоды времени. Формально-функциональная устойчивость первоначальной структуры позволяет выделить ее в качестве инварианта» [Янушкина web]. 
Архитектурный облик современного Волгограда образуют царицынские здания конца XIX - начала XX в., памятники довоенного конструктивизма, масштабная послевоенная застройка в стиле советского неоклассицизма, массовые типовые здания модернизма и архитектура постсоветского периода.

Значительную часть площади Волгограда составляет малоэтажный частный сектор, уже не гомогенный, включающий в себя достаточно большое количество новых красивых современных одно-, двух- и трехэтажных домов, которые, к сожалению, не всегда органично вписываются в окружающую среду.

Чудом сохранившиеся после Сталинградской битвы 1942-1943 гг. дореволюционные здания воспринимаются горожанами как ценные реликты прошлого, обретают статус памятников историко-культурного наследия, некоторые из них реставрируются и находятся под охраной государства. Преимущественно это бывшие купеческие особняки из красного кирпича, сильно выделяющиеся на фоне сталинской и позднесоветской архитектуры и создающие ощущение спокойной размеренной провинциальной жизни. К их числу относятся такие архитектурные памятники как Краеведческий и Мемориально-исторический музеи, Музыкально-драматический казачий театр, комплекс зданий бывшей немецкой колонии Сарепта.

Главной архитектурной доминантой Волгограда, формирующей его уникальный облик, является монументальный градостроительный ансамбль с четкой планировочной структурой, выполненный в русле классической традиции. Довоенный Сталинград строился как образцовый советский город. В послевоенный период он восстанавливался как город-герой, город монумент. Архитектурные решения, реализованные в Сталинграде в 1930-1950-х гг., были продиктованы советской идеологией и стали ее фундаментальной репрезентацией. Город имел выраженный символический статус в историко-культурном контексте сталинской эпохи. В архитектурном образе Сталинграда воплотились идеи Вечности, Памяти и Славы, тесно сопряженные с идеями Величия и Власти. Ключевые символы города - железнодорожный вокзал, здание Нового Экспериментального театра, Планетарий, ресторан «Маяк», триумфальная арка Волго-Донского канала, пропилеи и ротонда центральной Набережной 62-й армии. В стиле сталинского неоклассицизма выполнены здания Администрации области, главпочтамта, центрального банка, корпуса старейших университетов региона - социально-педагогического, медицинского, аграрного, здания медицинского назначения.

Несмотря на вторжение современных высоток в архитектурный ландшафт, монументальные ансамбли сталинской архитектуры по-прежнему формируют силуэт Волгограда. Расположенная по всей его протяженности (а это более 80 километров) послевоенная сталинская ансамблевая застройка отличается связанностью и органичностью. В сознании жителей города сталинская архитектура ассоциируется с красотой, престижем, высоким качеством жизни и не имеет негативных идеологических и политических коннотаций.

Большие пространства занимает типовая стандартизированная застройка позднесоветстского и постсоветского периода. Она не воспринимается горожанами как угнетающая своей монотонностью, а рассматривается как унифицированное демократичное доступное жилье, база для творчества и саморазвития (об этом свидетельствует многочисленность группы «Панельки» в социальной сети «В контакте» и ее содержательный контент).

«В архитектурном формообразовании Сталинграда, - пишет Янушкина, - решение вопросов образно-смысловой целесообразности преобладало над решением функциональных и социально-экономических проблем. Потребность в выражении героического духа времени побуждала архитекторов к синтетическому объединению форм, относящихся к различным историческим эпохам и культурам. Это обусловливало нарушение тектоники исходных пространственных типов, наслоение и кажущуюся эклектику форм, поскольку заимствование велось не по формальным и стилевым признакам, а по смысловым прототипам» [Янушкина web]. Аналогичная ситуация продолжается и сейчас. Не так давно установленный в центре Волгограда памятник Александру Невскому вызвал недоумение горожан и гостей города не только странным местоположением на одной из главных площадей города в центре проезжей части, но и неясно- 
стью причастности исторического лица и его образа к истории города.

В последние десятилетия на территории всей России идет поиск идентичности на основе дореволюционных традиций, национальных особенностей, этнической специфики. В Волгограде это выражается в обращении к образам Царицына, восстановлении представлений о нем как о крупном уездном городе с большим промышленным и культурным потенциалом. Визуальной репрезентацией этого процесса стали появившиеся в последние годы памятники казачеству (первому воеводе Царицына Григорию Засекину; памятник, в котором запечатлен момент проводов казака на войну; бюст героя трех войн казака К.И. Недорубова), а также памятник святым Петру и Февронии, памятник первому трамваю в Городском саду, скульптура первого кондуктора трамвая. Символом духовной защиты города стала бронзовая скульптура «Ангел-Хранитель» [Шипицин 2016].

Как отмечают Л.В. Щеглова и А.И. Шипицин, важной составляющей визуального образа Волгограда стала «жанровая городская скульптура, которая, в отличие от монументальных, суровых, патетичных памятников героическому прошлому Волгограда, не выражает большие идеи, а украшает и эмоционально насыщает городскую среду, делает ее более уютной и человечной. Корпоративный тип памятников подтверждает мысль о том, что в условиях «идеологической неопределенности», характерной для последних десятилетий, произведение, будучи избавленным от необходимости транслировать государственные идеалы и ценности, начинает выражать микро-идеологии города, организации или даже частного лица, инициировавших его создание» [Щеглова, Шипицин 2019].

Большое количество малых архитектурных форм, появившееся в последние годы свидетельство того, что город продолжает развиваться, живет как живой организм. Однако новые символы не выражают неповторимость места, а в самосознании волгоградцев по-прежнему преобладает сюжеты и темы города-героя и его главной высоты с символической доминантой - скульптурой «Родинамать зовет!». Но обладающая мощным культурообразующим ресурсом идея города-героя не слишком хорошо вписывается в современный контекст.

Архитектурный ландшафт современного Волгограда эклектичен, подобен постмодернистскому тексту. Он оказывается знаковым для города, который мог стать культурной столицей Нижневолжского региона, но пока еще не обрел определенного имиджа и региональной самобытности. Как показали социологические исследования, проведенные сотрудниками кафедры философии и культурологии Волгоградского государственного социально-педагогического университета, в Волгограде не сформирована позитивная региональная или городская идентичность [Шипицин, Марченко 2019].

Архитектура является важной составляющей образа города, который формируется в сознании людей и влияет на их мироощущение, ментальность, особенности взаимодействия и характер самореализации. Возникая как способ защиты от внешних воздействий, место отдыха, накопления сил, сохранения ценного и значимого, архитектурные сооружения в процессе человеческой творческой деятельности обретают художественное содержание, проявляющееся в пластике форм, декоре, цвете, композиции зданий и их сочетаний с ландшафтом, формируя эстетические переживания и создавая эмоциональные и психофизические состояния, организуя особый микроклимат, влияющий на людей и специфику их жизнедеятельности [Иконникова 1985; Саймондс 2013].

Образ города, как убедительно показал К. Линч, существует в сознании горожан как ментальная матрица, карта, обеспечивающая ориентацию в пространстве, предопределяющая характер представлений о природе мира, базовых убеждений, лежащих в основе всякой активности. Образ места проживания стратегическое звено, которое удерживается в подсознании человека и используется неявным образом в качестве матрицы, определяющей специфику интерпретации информации, определяя вектор деятельности [Линч 1982].

Восприятие - гибкий многогранный процесс. Как правило, мы воспринимаем то, что попадает в «зону видимости» нашей культуры. Однако каждый человек обладает сенсорным аппаратом с уникальной спецификой, которую можно развивать. 
Внешний мир во всем многообразии связей и богатстве оттенков смысла воспринимается на архетипическом, символическом и концептуальном уровнях. Архетипический неосознаваемый, связанный с биопсихофизиологической организацией человека и обусловленный его первоначальным единством с природой. Следствием восприятия мира на этом уровне, например, является орнамент, включающий в себя базовые пространственные составляющие (линия, круг, квадрат, ромб, спираль и другие геометрические элементы), конфигурация которых наделялась сакральным смыслом и использовалась в практических целях. На наличие в структуре сознания базовых элементов, организующих процесс восприятия, указывал Р. Арнхейм. Исследователь писал, что восприятие сложных пространственных композиций, силуэта, основывается на «схватывании» простейших элементарных форм: «Объективные содержания стимула вызывают в здоровой нервной системе воспринимающего субъекта вполне предсказуемые реакции. Это явление по общему признанию является элементарным» [Арнхейм 1974, 95]. Архетипический - уровень ощущений, предпосылка зарождающихся чувств, создающих эмоциональный фон, на котором протекают более осознанные процессы.

Символический уровень связан с познанием, отражает степень проникновения в природу реальности в актах мышления, включающих интуитивные прозрения, неявное знание и формально-логические установки.

Концептуальный уровень обусловлен знанием социокультурнорго контекста, идеологических предпосылок, конкретных теорий и обеспечивающих их жизненность институциональных практик - той картины мира, которая осознается и воспринимается как реальность настоящего, выстраиваемая рационально-логическим путем.

Мы можем ставить вопросы о проникновении на символический уровень, о знании и принятии концептуально оформленной информации, но архетипический уровень имеет значение независимо от нашего понимания и решения. Именно на этом уровне начинает формироваться идентичность как результат телесного, чувственного, эмоционального опыта нахождения в мире, мироощущение. Так, буду- чи погруженными в то или иное пространство, мы не просто оперируем категориями «далеко - близко», но испытываем чувство комфорта или дискомфорта, созерцаем красивое или стараемся не замечать безликое, обретая тем самым состояния сознания, которые лежат в основе нашей активности. Поэтому очень важна правильная, с точки зрения экологии человека, организация пространства. Гармоничные формы, экологичные материалы, красиво оформленные зоны пребывания людей могут оказывать большое влияние, став «мягкой силой», которая управляет, создавая со-стояния и стимулируя соответствующие отношения - с собой, с близким окружением, со средой, в которой осуществляется гармонизирующая перенасыщенный катаклизмами социальный мир повседневность [Забельшанский, Минервин, Рапопорт 1985].

Язык архитектуры складывается из знаковых форм, значение которых допускает интерпретацию, зависит от личности воспринимающего индивида, состояния его сознания, установок и восприятия [Бюхли 2017]. Среда предлагает условия, а наблюдатель может выбирать, наделять значением и смыслом то, что видит, формируя образы и структуры. Наблюдатель может играть активную роль в воспроизведении мира. Механизм этого процесса очень тонко и глубоко описал Г.А. Орлов: «Мир, такой, каким его видят и в котором живут носители данной культуры, не прячет свои сокровенные тайны в непостижимых трансцендентных сущностях, но постоянно открывает перед человеком возможность непосредственного приобщения к этим тайнам и их постижению. В этом мире идеи не существуют отдельно от феноменов, а субъект неотделим от объекта, потому что все заключенное в великом Единстве может быть постигнуто посредством бесконечно утончаемой чуткости и восприимчивости чувств. Чувства обращены как наружу, так и внутрь, и их совершенствование ведет человека по пути самопознания, неотличимого от познания окружающего мира. Знание и могущество такого человека могут стать необъятными, потому что он постепенно отождествляется с живыми предметами вокруг себя. Это отождествление с предметом рождает всепроникающую симпатию, которая единственная 
делает естественный порядок жизни доступным восприятию и дает знание естественных законов» [Орлов 1992, 23].

Социальная трансформация в России всегда сопровождалась тотальным разрушением, главным образом, символических артефактов предшествующей идеологической системы. Достаточно вспомнить массовое уничтожение храмовых сооружений в период советской власти, демонтаж памятников советской эпохи в настоящее время. Конфликт между историческим и современным контекстами неизбежен. Концептуальный, социальный смысл архитектурного наследия может утрачиваться. Но история знает немало примеров, когда архитектурные сооружения обретали художественную значимость и символический смысл. Почти всегда это было обусловлено их художественной ценностью, способностью оказывать влияние на психическое, физиологическое, эмоциональное состояние человека, сопряжено с опытом позитивного восприятия архитектурного объекта, раскрытием его уникальных особенностей, следствием чего оказывалось утверждение самобытности места, в котором находился объект.

Архитектура представляет собой своеобразную матрицу, в которой осуществляется жизнедеятельность людей. Вот уже многие десятки лет эта матрица имеет вид функциональной структуры, обеспечивающей реализацию утилитарных потребностей. Она стандартна и универсальна, что делает современные города такими похожими друг на друга. Идентичность связана с осознанием уникальности, постижением ценностей и смыслов, порожденных определенными обстоятельствами, сложившимися в конкретных пространственно-временных условиях, в определенном историко-культурном контексте.

Многие города России стремятся обрести позитивный имидж, находятся в поиске своей идентичности. Этот процесс идет и в городе-герое Волгограде, где еще не оформилась культурная парадигма и не очень высок уровень регионального самосознания. В поиске интегративных смыслов и ценностей общество может пойти по любому пути. Наиболее естественным представляется тот, который связан с обретением комфорта, возможностью получения ресурсных со- стояний вне зависимости от экономических, социальных, идеологических или иных факторов. Это делает необходимым более глубокое осмысление роли архитектурных образов в формировании ощущений, эмоций, состояний сознания и использования полученного опыта при решении практических архитектурных задач.

Современная идентичность формируется в результате осуществления новых социальных практик, позволяющих снимать традиционные ограничения. Важными факторами формирования идентичности являются яркие образы, способные вызывать сильные чувства и переживания в наблюдателе, устойчивые нарративы, раскрывающие особенности места. Для рискогенного, перенасыщенного социальными катаклизмами общества большое значение имеет создание ресурсообразующих зон, способствующих гармоничному развитию человека и обретению у него способностей оптимизировать окружающее пространство. Вдумчивое и осознанное отношение к созданию архитектурного ландшафта может стать основой общественной интеграции, важным условием формирования идентичности в условиях динамично развивающегося информационно детерминируемого общества.

\section{СПИСОК ЛИТЕРАТУРЫ}

Арнхейм $1974-$ Арнхейм Р. Искусство и визуальное восприятие. М.: Прогресс, 1974.

Бюхли 2017 - Бюхли B. Антропология архитектуры. Харьков: Гуманитар. центр, 2017.

Забельшанский, Минервин, Рапопорт, 1985 - Забельшанский Г.В. Минервин Г.В. Рапопорт Г.Ю. Архитектура и эмоциональный мир человека. М.: Стройиздат, 1985.

Иконникова 1985 - Иконникова А.В. Художественный язык архитектуры. М.: Искусство, 1985.

Колхас 2015 - Колхас Р. Мусорное пространство. М.: Арт Гид, 2015.

Линч 1982 - Линч К. Образ города. М.: Стройиздат, 1982.

Орлов 1992 - Орлов Г. Древо музыки. Вашингтон: Н.A. Frager \& Со; СПб.: Сов. композитор, 1992.

Саймондс 2013 - Саймондс Д.О. Ландшафт и архитектура М.: Кн. по требованию, 2013.

Щеглова, Щипицын 2019 - Щеглова Л.В., Щипииьын А.И. Архитектура Волгограда в культур- 
ных формах и социальных практиках горожан // Материалы III Международной научной конференции «Визуальная антропология 2019. Город-университет: жизненное пространство и визуальная среда». Великий Новгород: Изд-во Новгор. гос. ун-та им. Ярослава Мудрого, 2019. С. 250-263.

Шипицин 2016 - Шипицин А.И. Городская скульптура и культурный код Волгограда в контексте брендирования территории // Вестник ассоциации вузов туризма и сервиса. 2016. Т. 10. № 4. С. 89-95.

Шипицин, Марченко 2019 - Шипицин А.И., Марченко А.Ю. Актуальный имидж Волгограда глазами студенческой молодежи // Logos et Praxis. 2019. T. 18, №2. C. 109-117. DOI: https://doi.org/ 10.15688/lp.jvolsu.2019.2.10.

Янушкина web - Янушкина Ю.В. Особенности архитектурного формообразования в Сталинграде в историко-культурном контексте 1930-1950-х гг: автореф. дис. ... канд. архитектуры. Волгоград, 2009 // http://www.niitiag.ru/pub/pub_cat/ yanushkina_yu_v_osobennosti_arkhitekturnogo_ formoobrazovaniya_v_stalingrade.

\section{REFERENCES}

Arnheim R., 1974. Art and Visual Perception. Moscow, Progress Publ.

Bukhli V., 2017. Anthropology of Architecture. Kharkiv, Gumanitar. tsenter Publ.

Zabelshansky G.V., Minervin G.V. Rapoport G.Yu., 1985. Architecture and the Emotional World of Man. Moscow, Stroyizdat Publ.
Ikonnikova A.V., 1985. The Artistic Language of Architecture. Moscow, Iskusstvo Publ.

Koolhaas R., 2015. Waste Space. Moscow, Art Gid Publ.

Lynch K., 1982. The Image of the City. Moscow, Stroyizdat Publ.

Orlov G., 1992. Music Tree. Washington, N. A. Frager \& Co; St. Petersburg, Sov. kompozitor Publ.

Symonds D.O., 2013. Landscape and Architecture. Moscow, kn. po vostrebovaniyu Publ.

Shcheglova L.V., Schipitsyn A.I., 2019. The Architecture of Volgograd in Cultural Forms and Social Practices of Citizens. Proceedings of the III International Scientific Conference "Visual Anthropology City-University: Living Space and Visual Environment". Veliky Novgorod, Izd-vo Novgorodskogo gosudarstvennogo universiteta imeni Yaroslava Mudrogo, pp. 250-263.

Shipitsyn A.I., 2016. Urban Sculpture and the Cultural Code of Volgograd in the Context of Territory Branding. Bulletin of the Association of Universities of Tourism and Service, vol. 10, no. 4,pp. 89-95.

Shipitsyn A.I., MarchenkoA.Yu., 2019. The Actual Image of Volgograd Through the Eyes of Student Youth. Logos et Praxis, vol. 18, no. 2, pp. 109-117. DOI: https://doi.org/10.15688/lp.jvolsu.2019.2.10.

Yanushkina Yu.V., 2009. Features of Architectural Shaping in Stalingrad in the Historical and Cultural Context of the 1930-1950s: Abstract of Thesis for the Degree of Candidate of Architecture. Volgograd. URL: http://www.niitiag.ru/pub /pub_cat/ yanushkina_yu_v_osobennosti_ arkhitekturnogo_formoobrazovaniya_ v_stalingrade.

\section{Information About the Authors}

Viktoriya A. Khrapova, Doctor of Sciences (Philosophy), Professor, Department of Philosophy, Volgograd State University, Prosp. Universitetsky, 100, 400062 Volgograd, Russian Federation, khrapova@volsu.ru,https://orcid.org/0000-0002-5236-9147

Maria A. Latysheva, Candidate of Sciences (Philology), Associate Professor, Department of Linguistics and Intercultural Communication, Volgograd State Technical University, Prosp. Lenina, 28, 400005 Volgograd, Russian Federation, latyshevam@gmail.com, https://orcid.org/0000-0001-8890-1070

\section{Информация об авторах}

Виктория Анатольевна Храпова, доктор философских наук, профессор кафедры философии, Волгоградский государственный университет, просп. Университетский, 100, 400062 г. Волгоград, Российская Федерация, khrapova@volsu.ru, https://orcid.org/0000-0002-5236-9147

Мария Александровна Латышева, кандидат филологических наук, доцент кафедры лингвистики и межкультурной коммуникации, Волгоградский государственный технический университет, просп. Ленина, 28, 400005 г. Волгоград, Российская Федерация, latyshevam@gmail.com, https://orcid.org/0000-0001-8890-1070 